\title{
Free flap monitoring using an implantable Doppler probe
}

\author{
Rodney J French MD, James P O’Brien MD FRCSC, Gerald L Sparkes MD FRCSC, \\ Donald H Lalonde MD MSc FRCSC \\ Division of Plastic Surgery, Dalhousie University, Saint John Regional Hospital, Saint John, \\ New Brunswick
}

\section{RJ French, JP O'Brien, GL Sparkes, DH Lalonde. Free flap monitoring using an implantable Doppler probe. Can J Plast Surg 2001;9(6):233-238.}

Although clinical observation is the gold standard, the ideal free flap monitoring device has not been identified. The purpose of the present study was to review the first 14 months of experience using an implantable 20-MHz ultrasonic Doppler probe to monitor the microvascular anastamoses of free tissue transfers. Twenty-five flaps in 23 patients, with an average age of 51 years (age range 18 to 81 years), were performed. Probes were secured downstream of the venous anastamosis using a silicone-polyfluorotetraethylene sleeve. Doppler sounds were transduced before the flap was inset. Monitoring by nursing staff included conventional techniques (temperature, colour, capillary refill) and continuous Doppler flow monitoring. Dynamic diagnostic testing for anastomotic patency was facilitated by applying manual pressure on the flap to increase venous flow (the audible 'whoosh' sign) and valsalva manoeuvre to impede venous return momentarily (the 'heave' sign). Intraoperative vessel kinking, hematoma formation occluding venous outflow, and venous thrombosis were detected in four cases before concluding the procedure and corrected. Rapid, immediate cessation of audible flow was detected postoperatively in three of 25 flaps. Re-exploration (re-exploration rate 12\%) led to salvage of all three flaps (salvage rate 100\%). It was concluded from this study that flap re-exploration was prevented in four cases $(16 \%)$ because of intraoperative use of the implantable Doppler probe. Earlier detection of flap compromise perioperatively is thought to have contributed to the $100 \%$ salvage rate and to the $100 \%$ flap survival rate in the first 25 cases in which the implantable Doppler probe was used.

Key Words: Implantable Doppler probe; Free flap; Monitor

\section{Surveillance des greffes libres à l'aide d'une sonde Doppler implantable}

RÉSUMÉ : Même si l'observation clinique reste la norme en matière de surveillance, le dispositif idéal de surveillance des greffes libres n'a pas encore été trouvé. La présente étude a pour but de faire état des 14 premiers mois d'expérience de surveillance des anastomoses microvasculaires de greffes libres à l'aide d'une sonde Doppler implantable à ultrasons de $20 \mathrm{MHz}$. Vingt-cinq greffes ont été pratiquées sur 23 patients dont l'âge variait de 18 à 81 ans (âge moyen : 51 ans). Les sondes ont été fixées sur les anastomoses veineuses du côté des patients à l'aide d'un manchon de silicone et de polyfluorotétraéthylène. On a procédé à la transduction des signaux Doppler avant la mise en place du greffon. La surveillance par le personnel infirmier faisait appel aux techniques usuelles d'observation (température, couleur, remplissage capillaire) et à l'examen du signal Doppler continu. L'application d'une pression manuelle sur le greffon pour accroître le débit veineux (signe sonore « whoosh ») et la manœuvre de Valsalva pour gêner temporairement le retour veineux (signe du « dôme ») facilitaient l'examen diagnostique dynamique de la perméabilité des anastomoses. Dans quatre cas, on a décelé et corrigé, avant la fin de l'intervention, la présence d'une plicature vasculaire, la formation d'un hématome bloquant la circulation veineuse et la présence d'une thrombose veineuse. La perte rapide et immédiate du signal sonore en phase postopératoire a été perçue dans trois cas. Une nouvelle exploration (taux de reprise : $12 \%$ ) a permis de sauver les trois greffons (taux de sauvetage : $100 \%$ ). Aussi les résultats nous permettent-ils de conclure que le recours à la sonde Doppler implantable en cours d'intervention a permis d'éviter une nouvelle exploration du greffon dans quatre cas $(16 \%)$ et que la détection précoce d'atteinte à l'intégrité du greffon en phase périopératoire par la sonde a joué un rôle dans le taux de sauvetage de $100 \%$ et le taux de survie du greffon de $100 \%$ dans les 25 premiers cas.

This paper was presented at the 55th Annual Meeting of the Canadian Society of Plastic Surgeons, June 6 to 9, 2001, Jasper, Alberta Correspondence: Dr Donald H Lalonde, 705 Millidge Avenue, Saint John, New Brunswick E2K 2N7. Telephone 506-648-7950, fax 506-652-8042, e-mail huzil@health.nb.ca 
$\mathrm{W}$ hile success rates in free tissue transfer have risen dramatically over the past three decades, there has not been a corresponding increase in salvage rates after vascular compromise or thrombosis. The overall free flap success rate of $94 \%$ reported in 1984 (1) increased to $98.8 \%$ in a worldwide survey conducted in 1992 (2). Current salvage rates with conventional monitoring vary between $69 \%$ (3) and $77 \%$ (4), depending on the study. However, most large series report salvage rates below $50 \%(5-12)$.

It is well accepted that earlier detection of flap failure leads to higher salvage rates (4,13-16). Conventional monitoring techniques such as clinical observation, capillary refill, surface temperature and pin-prick testing have proven to be effective for detecting thromboses in free flaps (4,16-18), but the delay from the onset of venous thrombosis to clinically detectable flap compromise can be highly variable. Buried flaps, which have no externalized component, have limits on conventional monitoring, rely solely on Doppler probe evaluation of the pedicle and have a correspondingly higher failure rate $(4,16)$.

Many devices have been developed in an effort to detect flap compromise earlier, thereby improving flap salvage rates. These efforts have included muscle contractility testing (19), laser Doppler (20-28), tissue pH (29-31), pulse oximetry (32), surface temperature monitoring (33-35), intravenous fluorescein (36-39), Doppler ultrasonography (40-42), photoplethysmography (43-46), transcutaneous oxygen monitoring (47-50), and electrical impedance plethysmography (51). Each method has its advantages and disadvantages and none has been proven to be ideal. Although clinical observation is the gold standard, the ideal free flap monitoring device should provide a continuous recording of flap perfusion or flap metabolism with immediate detection of arterial

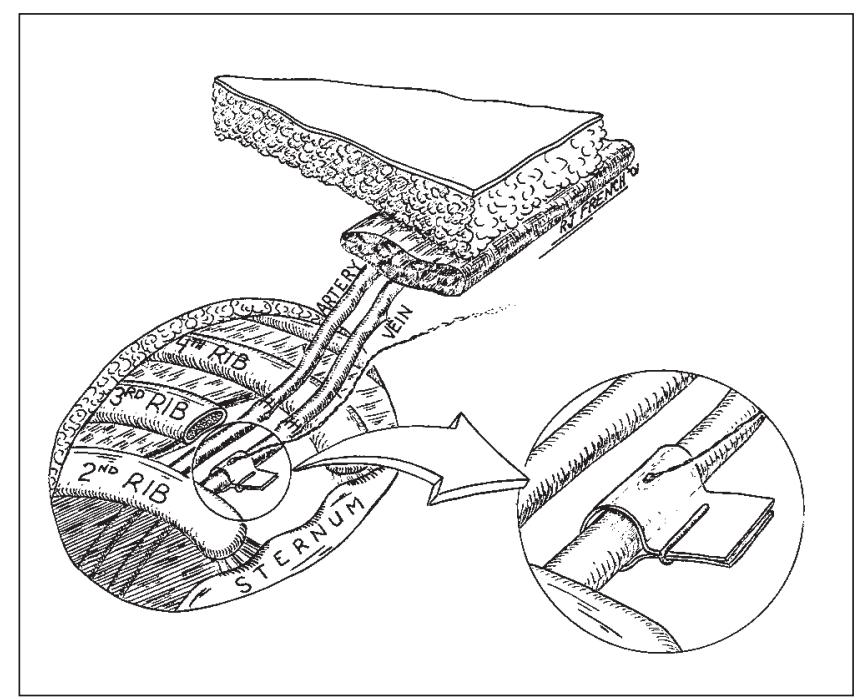

Figure 1) Pictorial example of the probe placement for left breast reconstruction using a free transverse rectus abdominus myocutaneous flap. The silicone cuff with a 20-MHz Doppler probe is placed downstream of the venous anastamosis, around the internal mammary vein. The transducing wire is placed parallel to the vein and is brought out through the wound or venous occlusion (52). Such a device should augment the clinical findings to improve salvage rates, rather than provide a substitute.

The use of an implantable Doppler probe was initiated at our institution in December 1999 in an effort to provide earlier detection of microvascular thromboses in free flaps. The purpose of the present study was to evaluate the success of free tissue transfers using the implanted venous Doppler probe, to document various technical modifications, and to evaluate its usefulness during flap insetting and postoperative monitoring in the first 25 free flaps in which it was used in our institution.

\section{PATIENTS AND METHODS}

A retrospective chart review was conducted for all patients who had free flap reconstruction with an implanted venous Doppler probe between December 1999 and February 2001. Charts were reviewed to evaluate patient demographics, flap type, location of transfer, ischemia time, need for reexploration, time of postoperative re-exploration, flap salvage and the overall success rate.

The interrupted suture technique was used for all anastamoses. At the conclusion of microvascular anastamosis, an implantable 20-MHz Cook-Swartz Doppler flow probe (model DP-SDP001, Cook Vascular Inc, USA) attached to a silicone-polytetrafluoroethylene cuff was placed around the vein, downstream of the anastamosis. The cuff was secured using a standard small vascular clip (Figure 1) with the transducing wire placed alongside the vein and brought out through the wound. The transducing wire was connected to a Doppler blood flow velocimeter (model DP-M100, Cook Vascular Inc, USA) and the sound quality and flow were confirmed. The flap was then assessed clinically for bleeding at the distal edges, capillary refill and arterial pulsations distal to the arterial anastamosis. Next, the flap was inset into the defect, with adjustments made according to reconstructive objectives, provided that the Doppler flow was still audible. Any loss in Doppler flow was interpreted as vascular compromise and investigated. The Doppler velocimeter was left on continuously throughout the closure of the wounds and during transfer of the patient to the stretcher, recovery room and to the burns and plastic surgery unit, Saint John Regional Hospital, Saint John, New Brunswick.

Nursing staff from the burns and plastic surgery unit met the patient and surgeon in the recovery room for continuity of care and to review with the surgeon the particular Doppler sounds for that patient. Nursing protocol involved flap assessment every $15 \mathrm{~min}$ for the first $24 \mathrm{~h}$ for colour, temperature, capillary refill, Doppler flow audibility and a compression test of the flap (the 'whoosh' sign) to hear increased venous outflow on the velocimeter. Surgical staff was contacted immediately for any change in the above parameters.

Intravenous antibiotics were routinely given intraoperatively and postoperatively for $48 \mathrm{~h}$. Acetylsalicylic acid $325 \mathrm{mg}$ was given once a day, antiembolism stockings were worn and low dose heparin $5000 \mathrm{U}$ was given subcutane- 


\section{TABLE 1}

Type of flap reconstruction performed in 23 consecutive patients at the Saint John Regional Hospital, Saint John, New Brunswick, between December 1999 and February 2001

\begin{tabular}{lc}
\hline Type of flap & Number \\
\hline Free TRAM & 12 \\
Perforator TRAM & 8 \\
Free rectus & 3 \\
Free fibula & 1 \\
Free radial forearm & 1 \\
Total & 25 \\
\hline
\end{tabular}

TRAM Transverse rectus abdominus myocutaneous

ously twice per day as prescribed. A caffeine-free diet was maintained for the duration of the hospital stay, but discontinued after discharge from hospital. The standard practice for breast reconstruction patients (majority of cases at the authors' institution) involves bed rest for $48 \mathrm{~h}$, progressive mobilization as tolerated by the patient on postoperative day 3 , and ambulation and discharge on postoperative day 4 or 5 , unless complications dictate otherwise.

\section{RESULTS}

Twenty-three consecutive patients who had 25 free flaps were included in the study. One patient had bilateral free transverse rectus abdominus myocutaneous (TRAM) flaps for immediate breast reconstruction and one patient had bilateral free perforator TRAM flap breast reconstruction. There were 20 female and three male patients. Patients ranged in age from 18 to 81 years, with a mean age of 51 years. The average ischemia time was $75 \mathrm{~min}$ (range 45 to $150 \mathrm{~min}$ ). The average number of days that patients were monitored with the Doppler probe was 3.9. Flap types are listed in Table 1 and flap locations are summarized in Table 2.

In the first 25 cases in which the Doppler probe was used, there were three instances of postoperative microvascular thrombosis or spasm detected in three patients, resulting in a re-exploration rate of $12 \%$. All three flaps were re-explored and salvaged in the operating room for a salvage rate of $100 \%$. In two cases, the nursing staff noted that the Doppler velocimeter went silent in a matter of seconds, with no clinical signs of flap compromise evident by the time of reexploration within the hour. This occurred 5 and $6 \mathrm{~h}$ postoperatively in these two cases, respectively. Milking of a small clot in the kinked vein was all that was required in one case, and a venous reanastamosis was required in the other. In the third case, which required re-exploration, the flap appeared to be clinically dusky one-half hour postoperatively, but the Doppler sound had not changed. Re-exploration was performed based on the change in clinical signs, but all vessels were found to be patent with good flow, and the flap survived without further intervention or mishap.

There were also four flaps whose blood supply was compromised intraoperatively. In each instance, a Doppler signal was satisfactorily obtained after microvascular anastamosis,
TABLE 2

Destination of flap reconstruction performed in 23 consecutive patients at the Saint John Regional Hospital, Saint John, New Brunswick, between December 1999 and February 2001

\begin{tabular}{lcc}
\hline Flap location & Number & $\begin{array}{c}\text { Per cent of total flap } \\
\text { reconstruction }\end{array}$ \\
\hline Breast & 19 & 76 \\
Head and neck & 2 & 8 \\
Upper extremity & 1 & 4 \\
Lower extremity & 3 & 12 \\
\hline
\end{tabular}

but subsequently went silent at a later stage in the operation. In the first instance, vein stripping of the adventitia was sufficient to re-establish blood flow and its concomitant Doppler signal. In a free TRAM case, the surgical team had completed the breast reconstruction and was closing the abdomen when the Doppler signal diminished. Closed manipulation of the breast re-established flow but within $10 \mathrm{~min}$ the sound diminished again. The flap was examined and found to be hyperbrisk on capillary refill. Re-exploration revealed a developing hematoma within the pocket and around the anastamoses. Blood flow resumed briskly with the evacuation of the hematoma and coagulation of an arterial bleeding event. The flap was re-inset but sound was lost again. This time the pedicle and rectus muscle had apparently become twisted while the hematoma had been evacuated. The flap was properly inset and no further complications developed throughout the patient's hospital stay or recovery. In the third case, the Doppler sound was lost on the insetting of the flap. This flap had an extremely long pedicle that was kinking and required manipulation to ensure that the pedicle would not kink once the flap was inset. In the fourth case, the skin envelope postmastectomy was too small to accommodate the flap. A tight closure coincided with the loss of the Doppler signal. The enlarging of the pocket was associated with a tension-free closure and a continuous audible Doppler signal.

Two probes failed mechanically in the early postoperative period (mechanical failure rate $8 \%$ ), and these flaps were followed clinically and healed. There was one false positive finding because the sound was lost from the probe, but this was restored by applying slight traction to the transducing wire to pull it back. One day later, the probe fell out when the patient coughed (postoperative day 3). This flap was followed clinically thereafter and healed without incident. Another false positive finding was due to battery failure that was correctly identified and remedied. There were no false negative findings.

There were no instances of interference from other monitoring devices within the hospital. Probes were easily removed by slight traction being applied to the external wire. No adverse effects, such as vessel disruption or thrombosis, were associated with the removal of the probes. There have been no instances of extrusion of the silicone cuff. 
There were two postoperative wound infections, but both were in the donor abdominal incisions and healed with standard antibiotic therapy. One abdominal hernia developed in the donor site of a free TRAM flap and this hernia was repaired by the attending surgeon six months postoperatively. No flaps were lost following discharge from hospital.

\section{DISCUSSION}

Microvascular thrombosis at the site of anastamosis is the most dreaded and unavoidable potential complication in free tissue transfers. Irrespective of the experience of the surgical team or the reliability of the flap selected, vascular compromise of free flaps will occur on occasion and require urgent re-exploration if salvage is to be expected. Re-exploration rates may vary among centres and among different studies, but surgical re-exploration is nonetheless an unfortunate reality. Because success rates in free tissue transfer in most large series now exceed $95 \%(2,4,8,14,16,53)$, rapid identification of the failing flap and early re-exploration in the operating room are required to optimize the overall success rates of free tissue transfers.

It has been well documented that the success of free tissue transfer is enhanced by the early and rapid identification of flap compromise $(4,14-16)$. Kerrigan et al (15) have shown that flaps tolerate a second ischemic event in the form of postoperative thrombosis very poorly. They stressed the importance of vigilant postoperative supervision and the potential importance of monitors. Increasing periods of flap ischemia lead to an obstructive 'no-reflow' phenomenon that becomes irreversible after $12 \mathrm{~h}$ and ultimately leads to flap death (54). Kroll et al (8) were unable to salvage failing flaps beyond the third postoperative day. They theorized that this was secondary to a decrease in the frequency of flap checks to every $4 \mathrm{~h}$ after the third postoperative day. Hidalgo and Jones (14) took an aggressive approach to early reexploration and were able to increase their flap survival from $90 \%$ to $98 \%$.

While many free flap monitoring techniques have been described, none have been optimal or enjoyed wide-spread acceptance. Most techniques are an indirect measurement of vascular status, rather than direct, and few techniques provide a method of continuous monitoring. In the largest study to date, Disa and colleagues (4) reviewed 750 consecutive flaps. They found that conventional monitoring with a welltrained staff was highly effective for visible flaps, but buried flaps still relied on guesswork (4). This guesswork resulted in none of their failed buried flaps being salvageable. An implantable Doppler probe offers a theoretical advantage because of the instantaneous, direct measurement of vascular status that it provides and its application for buried flaps.

The implantable Doppler provided a window to the underlying gross anatomical relationships that could not be appreciated by observation of the external flap alone. Beyond its intended postoperative monitoring capabilities, the implantable Doppler acted as a preventative device in the present study when it correctly identified four compromised pedicles intraoperatively. The four flaps readjusted at the time of in- setting had clearly lost venous outflow and certainly would have required re-exploration postoperatively. Each of these flaps lacked the standard clinical signs of vascular compromise: venous discolouration, venous oozing on pin-prick, change in capillary refill and decreased surface temperature. The immediacy of the implantable Doppler probe detection of venous compromise does not permit clinical signs to manifest. There is a finite amount of time required for venous congestion to fill the capacitance vessels of the flap before the skin capillaries begin to fill with venous blood and show the classic clinical signs of flap compromise. As Swartz et al (55) have shown, the venous capacitance of a flap is directly proportional to the time it takes to clinically note venous insufficiency in an experimental flap whose vein is occluded. For some muscle flaps, the venous capacitance may be large enough that arterial pulsations will continue in the flap for up to $5 \mathrm{~h}$ (56). A more favourable outcome was obtained in these four cases by having the implantable Doppler probe signal intraoperatively. A further intangible benefit may be the positive effect on the outcome of performing a necessary reanastamosis or flap re-exploration during daytime hours, with the regular nursing staff assisting. Without the implantable Doppler probe, it may have been a few hours before venous compromise was detected clinically.

We found this device to be very useful in insetting the flap intraoperatively. Kinking, twisting or compressing of the pedicle was immediately detected while the patient was still on the operating table, and we believed that this most likely prevented delayed detection of loss of blood flow and possible return to the operating room.

There was a learning curve to using the implantable Doppler probe. Initial attempts to suture the silicone cuff to the vein were time consuming and frustrating. Applying a vascular clip to the cuff, as recommended by Dr William Swartz (Pittsburgh, Pennsylvania; personal communication), provided an accurate and rapid method of probe application. The placement of the probe adds only seconds to the procedure, but provides instantaneous, continuous feedback on the vascular status of the flap.

The learning curve extended to postoperative care. Nurses and physicians had to 'get out of' the arterial Doppler recognition and 'get into' the sounds of the venous Doppler probe, which are quite different. The normal sound is best described as a howling wind or the sound of the ebb and rush of the ocean. However, both surgical and nursing staff quickly became accustomed to the 'normal' sound. In one instance, a dusky flap was re-explored even though the Doppler signal was present. This incident occurred during the initial months of the present study when confidence in the probe had not been established. The flap anastamoses were found to be patent and flowing, and the flap healed without intervention. In two cases the Doppler signal went silent and this was noted immediately by nursing staff. It was in these two instances that the 'whoosh' and 'heave' signs evolved. Although described originally by Swartz et al (55) as signal augmentation due to pressure on the flap, the 'whoosh' sign is the audible rapid increase in pitch and velocity of the Doppler signal and is elicited by pressing on the flap. It repre- 
sents the expulsion of venous blood from the flap, analogous to compressing a sponge full of water. Nursing staff or junior medical staff at the bedside can perform this quick assessment and its presence can give immediate feedback on the vascular outflow from the flap. The 'heave' sign is the natural counterpart to the 'whoosh' sign. A valsalva manoeuvre performed by the patient decreases venous return to the heart due to an increase in intrathoracic pressure. This increase in pressure, in turn, decreases venous return from the flap and is heard as a decrease in venous sound from the Doppler probe during the valsalva. Both of these signs are a dynamic test of the direct input from the Doppler signal. The signs were absent in the cases that were re-explored due to loss of the Doppler signal.

It is worthy to note that in the two cases of probe failure and the one case of accidental traumatic removal, conventional monitoring techniques only were used thereafter. Each of the flaps healed without incident. The use of the implantable Doppler is a very useful adjunct, but must still be interpreted within the context of the clinical signs of flap viability.

We had one case of a buried flap. This flap was a tubed radial forearm free flap used to reconstruct the circumferential pharynx after total pharyngectomy and laryngectomy. The presence of the Doppler signal throughout the immediate postoperative course, combined with positive 'heave' and 'whoosh' signs assured flap viability. This course likely

\section{REFERENCES}

1. Shaw WW. Microvascular free flaps: survival, donor sites, and applications. In: Buncke HJ, Furnas DW, eds. Symposium on Clinical Frontiers in Reconstructive Microsurgery. St Louis: Mosby, 1984.

2. Khouri RK. Avoiding free flap failure. Clin Plast Surg 1992;19:773-82.

3. Khouri RK, Cooley BC, Kunselman AR, et al. A prospective study of microvascular free-flap surgery and outcome. Plast Reconstr Surg 1998;102:711-21.

4. Disa JJ, Cordeiro PG, Hidalgo DA. Efficacy of conventional monitoring techniques in free tissue transfer: An 11-year experience in 750 consecutive cases. Plast Reconstr Surg 1999;104:97-101.

5. Harashina T. Analysis of 200 free flaps. Br J Plast Surg 1988;41:33-6.

6. Irons GB, Wood MB, Schmitt EH. Experience with one hundred consecutive free flaps. Ann Plast Surg 1987;18:17-23.

7. Khouri RK, Shaw WW. Reconstruction of the lower extremity with microvascular free flaps: A 10-year experience with 304 consecutive cases. J Trauma 1989;29:1086-94.

8. Kroll SS, Schusterman MA, Reece GP, et al. Timing of pedicle thrombosis and flap loss after free-tissue transfer. Plast Reconstr Surg 1996;98:1230-3.

9. Rieck B, Mailander P, Machens HG. Vascular complications after free tissue transfer. Microsurgery 1995;16:400-3.

10. Schusterman MA, Miller MJ, Reece GP, Kroll SS, Marchi M, Goepfert H. A single center's experience with 308 free flaps for repair of head and neck cancer defects. Plast Reconstr Surg 1994;93:472-8.

11. Simpson KH, Murphy PG, Hopkins PM, Batchelor AG. Prediction of outcomes in 150 patients having microvascular free tissue transfers to the head and neck. Br J Plast Surg 1996;49:267-73.

12. Urken ML, Weinberg H, Buchbinder D, et al. Microvascular free flaps in head and neck reconstruction. Report of 200 cases and review of complications. Arch Otolaryngol Head Neck Surg 1994;120:633-40.

13. Goodstein WA, Buncke HJ. Patterns of vascular anastamoses vs. success of free groin flap transfers. Plast Reconstr Surg 1979;64:37-40.

14. Hidalgo DA, Jones CS. The role of emergent exploration in free-tissue represented a rare instance where the 'whoosh' and the 'heave' signs could be used for a buried flap. Flap survival was later confirmed on clinical examination by the otolaryngologist four weeks after the operation.

All studies have limitations. The present study is limited by the small sample size and retrospective chart review format. Because of these limitations, firm conclusions regarding the benefits of the implantable Doppler probe cannot be drawn. However, even with the limited number of flaps performed in the Saint John Regional Hospital, our initial experience with the implanted Doppler probe has been very encouraging. Our first 25 cases with the Doppler have resulted in a $100 \%$ survival rate. The audible changes heard while manipulating flaps are astounding and remarkable. It appears to be invaluable during flap inset, provides the early detection required to achieve a high flap salvage rate when used in conjunction with conventional monitoring techniques, and has undetermined potential for buried free flap monitoring.

ACKNOWLEDGEMENTS: The authors thank the dedicated nursing staff of the burns and plastic surgery unit of the Saint John Regional Hospital whose initiative, attentiveness, and constructive feedback have directly contributed to the success rates achieved in this study. The authors have not and will not receive any royalties from the manufacture, distribution, sale or clinical use of the CookSwartz vascular probes.

transfer: A review of 150 consecutive cases. Plast Reconstr Surg 1990;86:492-8.

15. Kerrigan CL, Zelt RG, Daniel RK. Secondary critical ischemia time of experimental skin flaps. Plast Reconstr Surg 1984;74:522-6.

16. Kind GM, Buntic RF, Buncke GM, Cooper TM, Siko PP, Buncke HJ Jr. The effect of an implantable Doppler probe on the salvage of microvascular tissue transplants. Plast Reconstr Surg 1998;101:1268-73.

17. Furnas H, Rosen JM. Monitoring in microvascular surgery. Ann Plast Surg 1991;26:265-72.

18. Jones BM. Predicting the fate of free tissue transfers. Ann R Coll Surg Engl 1985;67:63-70.

19. Davison PM, Batchelor AG, Wilson GR, Sully L. The muscle twitch monitor: A rapid unequivocal method of monitoring free muscle transfers. Br J Plast Surg 1986;39:356-60.

20. Bruce-Chwatt AJ. Free flap monitoring using a microcomputer linked to a laser Doppler flowmeter. Br J Plast Surg 1986;39:229-38.

21. Clinton MS, Sepka RS, Bristol D, et al. Establishment of normal ranges of laser Doppler blood flow in autologous tissue transplants. Plast Reconstr Surg 1991;87:299-308.

22. Goldberg J, Sepka RS, Perona BP, Pederson WC, Klitzman B. Laser Doppler blood flow measurements of common cutaneous donor sites for reconstructive surgery. Plast Reconstr Surg 1990;85:581-6.

23. Heden PG, Hamilton R, Arnander C, Jurell G. Laser Doppler surveillance of the circulation of free flaps and replanted digits. Microsurg 1985;6:11-9.

24. Jenkins SD, Sepka RS, Barwick WJ, Serafin D, Klitzman B. Routine clinical use of laser Doppler flowmeter to monitor free tissue transfer: Preliminary results. J Reconstr Microsurg 1987;3:281-3.

25. Jenkins S, Sepka R, Barwick WJ. Routine use of laser Doppler flowmetry for monitoring autologous tissue transplants. Ann Plast Surg 1988;21:423-6.

26. Jones BM, Mayou BJ. The laser Doppler flowmeter for microvascular monitoring: A preliminary report. Br J Plast Surg 1982;35:147-9.

27. Svensson H, Pettersson H, Svedman P. Laser Doppler flowmetry and 
laser photometry for monitoring free flaps. Scand J Plast Reconstr Surg 1985;19:245-9.

28. Walkinshaw M, Holloway A, Bulkley A, Engrav LH. Clinical evaluation of laser Doppler blood flow measurements in free flaps. Ann Plast Surg 1987;18:212-7.

29. Dunn RM, Kaplan IB, Mancoll J, Terzis JK, Trengove-Jones G. Experimental and clinical use of $\mathrm{pH}$ monitoring of free tissue transfers. Ann Plast Surg 1993;31:539-45.

30. Raskin DJ, Erk Y, Spira M, Melissinos EG. Tissue pH monitoring in microsurgery: a preliminary evaluation of continuous tissue $\mathrm{pH}$ monitoring as an indicator of perfusion disturbances in microvascular free flaps. Ann Plast Surg 1983;11:331-9.

31. Warner KG, Durham-Smith G, Butler MD, Attinger CE, Upton J, Khuri SF. Comparative response of muscle and subcutaneous tissue $\mathrm{pH}$ during arterial and venous occlusion in musculocutaneous flaps. Ann Plast Surg 1989;22:108-16.

32. Graham B, Paulus DA, Caffee HH. Pulse oximetry for vascular monitoring in upper extremity replantation surgery. J Hand Surg [Am] 1986;11:687-92.

33. Kaye JJ. A reliable, inexpensive temperature monitor for microsurgery. Orthop Rev 1987;16:630-2.

34. Khouri RK, Shaw WW. Monitoring free flaps with surface temperature recordings: Is it reliable? Plast Reconstr Surg 1992;89:495-9; discussion 500-2.

35. Leonard AG, Brennen MD, Colville J. The use of continuous temperature monitoring in the post-operative management of microvascular cases. Br J Plast Surg 1982;35:337-42.

36. Copeland J, Harman RD, Wells HG, Puckett CL. Quantitative fluorometry as a monitor for microvascular surgery. J Hand Surg [Am] 1987; 12:250-5.

37. Graham BH, Gordon L, Alpert BS, Walton R, Buncke HJ, Leitner DW. Serial quantitative skin surface fluorescence: a new method for postoperative monitoring of vascular perfusion in revascularized digits. J Hand Surg [Am] 1985;10:226-30.

38. Harii K, Ohmori K, Torii S, Sekiguchi J. Microvascular free skin flap transfer. Clin Plast Surg 1978;5:239-63.

39. Morrison WA, O'Brien BM, Macleod A. Clinical experiences in free flap transfer. Clin Orthop 1978;133:132-9.

40. Jones BM, Greenhalgh RM. The use of the ultrasound Doppler flowmeter in reconstructive microvascular surgery. Br J Plast Surg 1983;36:245-53.

41. Solomon GA, Yaremchuk MJ, Manson PN. Doppler ultrasound surface monitoring of both arterial and venous flow in clinical free tissue transfers. J Reconstr Microsurg 1986;3:39-41.

42. Van Beek AL, Link WJ, Bennett JE, Glover JL. Ultrasound evaluation of microanastamosis. Arch Surg 1975;110:945-9.

43. Baudet J, LeMaire JM, Guimberteau JC. Ten free groin flaps. Plast Reconstr Surg 1976;57:577-95.

44. Doyle DJ, Eng P. A microminiature photoplethysmograph probe for microvascular surgery. Microsurgery 1984;5:105-6.

45. Harrison DH, Girling M, Mott G. Experience in monitoring the circulation in free flap transfers. Plast Reconstr Surg 1981;68:543-55.

46. Webster MH, Patterson J. The photoelectric plethysmograph as a monitor of microvascular anastamoses. Br J Plast Surg 1976;29:182-5.

47. Achauer BM, Black KS, Litke DK. Transcutaneous $\mathrm{PO}_{2}$ in flaps: a new method of survival prediction. Plast Reconstr Surg 1980;65:738-45.

48. Achauer BM, Black KS. Transcutaneous oxygen and flaps. Plast Reconstr Surg 1984;74:721-2.

49. Serafin D, Lesesne CB, Mullen RY, Georgiade NG. Transcutaneous $\mathrm{PO}_{2}$ monitoring for assessing viability and predicting survival of skin flaps: experimental and clinical correlations. J Microsurg 1981;2:165-78.

50. Smith AR, Sonneveld GJ, Kort WJ, van der Muelen JC. Clinical application of transcutaneous oxygen measurements in replantation surgery and free tissue transfer. J Hand Surg [Am] 1983;8:139-45.

51. Harrison DH, Mott G. Impedance monitoring for subcutaneous free flap transfers. Br J Plast Surg 1989;42:318-23.

52. Jones NF. Intraoperative and postoperative monitoring of microsurgical free tissue transfers. Clin Plast Surg 1992;19:783-97.

53. Swartz WM, Izquierdo R, Miller MJ. Implantable venous Doppler microvascular monitoring: Laboratory investigation and clinical results. Plast Reconstr Surg 1994;93:152-63.

54. May JW Jr, Chait LA, O'Brien BM, Hurley JV. The no-reflow phenomenon in experimental free flaps. Plast Reconstr Surg 1978;61:256-67.

55. Swartz WM, Jones NF, Cherup L, Klein A. Direct monitoring of microvascular anastamoses with the 20-MHz ultrasonic Doppler probe: An experimental and clinical study. Plast Reconstr Surg 1988;81:149-58 